\title{
Enzima e simbiótico para frangos criados nos sistemas convencional e alternativo
}

\author{
Enzyme and symbiotic for broilers bred in conventional and alternative systems
}

\author{
José Roberto Sartori ${ }^{I}$ Kelly Almeida Pereira ${ }^{\text {II }}$ Jane Cristina Gonçalves ${ }^{\text {III }}$ \\ Valquíria Cação da Cruz ${ }^{\mathrm{III}}$ Antonio Celso Pezzato
}

\section{RESUMO}

\begin{abstract}
O objetivo deste trabalho foi estudar os efeitos da inclusão de enzima e simbiótico nas rações de frangos de corte criados nos sistemas convencional e alternativo sobre o desempenho, rendimento de carcaça, cortes e gordura abdominal e também avaliar economicamente o uso destes aditivos em ambos os sistemas de criação. Foram utilizados 720 pintos machos Cobb, com um dia de idade, distribuídos em um delineamento em blocos casualizados no esquema fatorial 2x3, com dois sistemas de criação: convencional (com promotor de crescimento) e alternativo (sem promotor de crescimento) e três aditivos: sem outro aditivo (SA), com simbiótico (SI) e com enzima + simbiótico (SIE), com 4 repetições de 30 aves cada. Aos 42 dias de idade, o fator de produção $(F P)$ foi menor $(P<0,05)$ para aves $S A(324)$, quando comparadas às tratadas com SI (334) e SIE (337). Aves criadas no sistema convencional apresentaram maior $(P<0,05) F P$ (338), quando comparadas às do sistema de criação alternativo (325). No sistema alternativo, a conversão alimentar foi melhor $(P<0,05)$ para aves SI $(1,77)$, quando comparadas às SIE $(1,82)$ e SA $(1,85)$. O uso de SI e SIE favorece o desempenho dos frangos aos 42 dias de idade e não influencia o rendimento de carcaça, cortes e gordura abdominal, tanto no sistema convencional como no alternativo, sendo que estes aditivos aumentam os custos de produção em ambos os sistemas. $O$ sistema alternativo de criação proporciona maior retorno econômico, apesar do menor fator de produção.
\end{abstract}

Palavras-chave: aves, desempenho, promotor de crescimento, rendimento de carcaça.

\section{ABSTRACT}

This research was aimed at evaluating the effects of enzyme and symbiotic inclusion in broilers diets bred in conventional and alternative systems on performance, carcass yield, cuts, abdominal fat and economic return these additives in both breeding systems. 720 one-day old male Cobb chicks were distributed in randomized blocks design according to a $2 \times 3$ factorial, two breeding systems: conventional (with growth promoter) and alternative (no growth promoter) and three additives: no additive (NA), symbiotic (SY) and symbiotic + enzyme (SYE), with four replicates of 30 broilers each. At 42 days old, the production factor (PF) was lower in NA broiler chickens (324) as broiler chickens supplemented with SY (334) and SYE (337). Broiler bred in conventional system showed higher PF (338) as broilers bred in alternative system (325). In alternative breeding system, the feed conversion was better in SY broilers (1.77) as SYE (1.82) and NA (1.85) broilers. The SY and SYE use improve the performance of broiler chickens at 42 days old and it doesn't affect carcass yield, cuts, and abdominal fat, in conventional or alternative system; moreover these additives increase production costs in both systems. Alternative system provide higher economic return, despite of lower production factor.

Key words: carcass yield, growth promoter, performance, poultry.

\section{INTRODUÇÃO}

A inclusão de enzimas e probióticos nas rações de frangos de corte pode ser uma alternativa para se trabalhar com rações sem promotor de crescimento no sistema de criação alternativo, que consiste em uma ave criada sem uso de antibióticos, anticoccidianos, promotores de crescimento,

\footnotetext{
'Departamento de Melhoramento e Nutrição Animal (DMNA), Faculdade de Medicina Veterinária e Zootecnia (FMVZ), Universidade Estadual Paulista (UNESP), Botucatu, SP, Brasil. CP 560, 18618-000. E-mail: jrsartori@fca.unesp.br. Autor para correspondência.

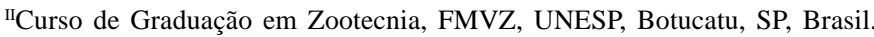

IIIPrograma de Pós-graduação em Zootecnia, FMVZ, UNESP, Botucatu, SP, Brasil.
} 
quimioterápicos e ingredientes de origem animal na dieta, além de menor densidade de aves e de uma série de outros requisitos e normas aprovadas e oficializadas no âmbito da Associação da Avicultura Alternativa, AVAL(DEMATTÊ FILHO, 2004).

Os probióticos podem ser definidos como suplemento alimentar composto de cultura definida ou indefinida de microorganismos vivos (MACHADO, 2000). Podem colonizar o organismo, promover um melhor equilíbrio da flora intestinal, estimular a imunidade e a produção de enzimas digestivas e vitaminas do complexo $\mathrm{B}$, aumentar a imunidade da mucosa intestinal e protegê-la contra toxinas préformadas por outros organismos (FULLER, 1989). Independentemente de sua via de aplicação (ração, água e outros), os probióticos devem ser utilizados o mais precocemente possível nas aves, a fim de que as bactérias presentes no produto multipliquem-se e colonizem o trato intestinal, iniciando suas atividades benéficas ao hospedeiro antes desse ser contaminado por algum patógeno (ANDREATTI FILHO \& SAMPAIO, 1999).

O conceito de simbiótico alia o fornecimento de microrganismos probióticos juntamente com substâncias prebióticas específicas que estimulem seu desenvolvimento e atividade, potencializando o efeito de ambos os produtos (MENTEN, 2002). SCHWARZ (2002) concluiu que é perfeitamente possível substituir os antibióticos por probióticos, prebióticos e simbióticos, sem perdas no desempenho das aves.

O uso de enzimas exógenas em dietas para aves pode aumentar a digestibilidade dos nutrientes e o valor nutritivo das dietas formuladas com milho e soja, resultando em melhor desempenho de frangos (SOTO-SALANOVA et al., 1996). GARCIA et al. (2000) concluíram que a adição de complexo multienzimático em rações com farelo de soja integral extrusada para frangos (1-42 dias) foi efetiva na melhora da utilização de energia metabolizável, proteína e aminoácidos (Met, Met+Cis e Lis) em 9, 7 e 5\%, respectivamente.

O presente trabalho teve por objetivo avaliar os efeitos da inclusão de enzima e simbiótico nas rações de frangos de corte criados nos sistemas convencional e alternativo sobre o desempenho, rendimento de carcaça, cortes e gordura abdominal, além de avaliar economicamente os tratamentos em ambos os sistemas de criação.

\section{MATERIAL E MÉTODOS}

O experimento foi conduzido no aviário do Laboratório de Nutrição de Aves da Faculdade de
Medicina Veterinária e Zootecnia, UNESP - Campus de Botucatu, no período de 17 de julho a 28 de agosto de 2002. Foram utilizados 720 pintinhos de corte machos, com 1 dia de idade, vacinados no incubatório contra doenças de Gumboro, Marek e Bouba aviária e, via aspersão, contra coccidiose.

As aves foram distribuídas no delineamento em blocos casualizados no esquema fatorial $2 \times 3$, com dois sistemas de criação: convencional - CO (com promotor de crescimento) e alternativo - AL (sem promotor de crescimento) e três aditivos: sem outro aditivo (SA), com simbiótico (SB) e com simbiótico + enzima (SBE), com quatro repetições de 30 aves cada.

Os pintinhos foram alojados em 24 boxes de 2,5 $\mathrm{m}^{2}$, com 30 aves/boxe, numa densidade de 12 aves $\mathrm{m}^{-2}$, em aviário tipo convencional. O aquecimento durante o período inicial foi proporcionado por lâmpadas infravermelhas, uma para cada boxe. O fornecimento de água e ração inicial foi feito através de bebedouro e comedouro inicial tipo copo de pressão, respectivamente, um para cada boxe. Estes equipamentos foram substituídos gradativamente por bebedouro pendular e comedouro tubular definitivos, um para cada boxe, respectivamente. A temperatura e a ventilação foram controladas manualmente, manejandose as cortinas laterais do galpão. O programa de luz foi constante, com o fornecimento de 24 horas de luz. As rações foram formuladas segundo recomendações de ROSTAGNO et al. (2000), considerando-se as fases de criação pré-inicial, inicial, crescimento e final (Tabela 1).

As aves dos tratamentos com simbiótico receberam dois gramas de probiótico (Colostrum Avis ${ }^{\circledR}$ ) na forma de péletes no primeiro dia de vida. Antes do fornecimento da ração e até os 37 dias de idade, foi adicionado o produto simbiótico (Simbiótico Plus ${ }^{\circledR}$ ) na ração, na dosagem de dois quilogramas por tonelada. Os tratamentos com simbiótico + enzima, além do descrito acima, receberam 200g da enzima (Bioenzima ${ }^{\circledR}$, complexo enzimático com a-amilase, 15.033U/g, lipase, $601 \mathrm{U} \mathrm{g}^{-1}$, celulase, 802U g-1 $\mathrm{U}^{-1}$ protease, $3.608 \mathrm{U} \mathrm{g}^{-1} \mathrm{e}$ pectinase, $401 \mathrm{U} \mathrm{g}^{-1}$ ) por tonelada de ração até 37 dias de idade. Água e ração foram fornecidas à vontade durante todo o período experimental.

Os dados para desempenho foram obtidos para os períodos acumulados de 1 a 21 e de 1 a 42 dias de idade. Para tanto, foram coletados e calculados os seguintes índices: peso corporal (as aves de cada boxe foram pesadas juntas, no alojamento, aos 21 e 42 dias de idade); ganho de peso (obtido pela diferença entre o peso ao final de cada período e o peso inicial no alojamento); consumo de ração (obtido pela diferença

Ciência Rural, v.37, n.1, jan-fev, 2007. 
Tabela 1 - Composição percentual e valores calculados das rações.

\begin{tabular}{|c|c|c|c|c|c|c|c|c|}
\hline \multirow{2}{*}{ Ingredientes (\%) } & \multicolumn{4}{|c|}{ Sistema convencional } & \multicolumn{4}{|c|}{ Sistema alternativo } \\
\hline & Pré-inicial & Inicial & Crescimento & Final & Pré-inicial & Inicial & Crescimento & Final \\
\hline Milho & 57,00 & 59,70 & 62,43 & 66,65 & 57,00 & 59,70 & 62,43 & 66,65 \\
\hline Farelo de soja & 36,85 & 34,10 & 31,00 & 27,63 & 36,85 & 34,10 & 31,00 & 27,63 \\
\hline Fosfato bicálcico & 0,32 & 0,20 & 0,10 & 0,00 & 0,32 & 0,20 & 0,10 & 0,00 \\
\hline Calcítico & 0,30 & 0,25 & 0,14 & 0,08 & 0,30 & 0,25 & 0,14 & 0,08 \\
\hline Sal comum & 0,08 & 0,05 & 0,02 & 0,00 & 0,08 & 0,05 & 0,02 & 0,00 \\
\hline L- lisina & 0,18 & 0,18 & 0,18 & 0,19 & 0,18 & 0,18 & 0,18 & 0,19 \\
\hline Stafac500 & 0,002 & 0,002 & 0,002 & 0,00 & 0,00 & 0,00 & 0,00 & 0,00 \\
\hline Óleo de soja & 2,05 & 2,30 & 2,90 & 2,45 & 2,05 & 2,30 & 2,90 & 2,45 \\
\hline Núcleo* & 3,00 & 3,00 & 3,00 & 3,00 & 3,00 & 3,00 & 3,00 & 3,00 \\
\hline Porção variável & $0,22^{1}$ & $0,23^{2}$ & $0,23^{2}$ & 0,00 & $0,22^{3}$ & $0,23^{4}$ & $0,23^{4}$ & 0,00 \\
\hline \multicolumn{9}{|l|}{ Valores Calculados } \\
\hline Energia metab. (kcal/kg) & 2.952 & 3.003 & 3.076 & 3.103 & 2.952 & 3.003 & 3.076 & 3.103 \\
\hline Proteína bruta (\%) & 21,91 & 20,89 & 19,70 & 18,53 & 21,91 & 20,89 & 19,70 & 18,53 \\
\hline Cálcio (\%) & 0,99 & 0,94 & 0,89 & 0,83 & 0,99 & 0,94 & 0,89 & 0,83 \\
\hline Fósforo disponível (\%) & 0,46 & 0,44 & 0,41 & 0,39 & 0,46 & 0,44 & 0,41 & 0,39 \\
\hline Fibra bruta (\%) & 3,37 & 3,26 & 3,13 & 2,93 & 3,37 & 3,26 & 3,13 & 2,93 \\
\hline Metionina (\%) & 0,52 & 0,50 & 0,46 & 0,44 & 0,52 & 0,50 & 0,46 & 0,44 \\
\hline Lisina (\%) & 1,31 & 1,24 & 1,16 & 1,08 & 1,31 & 1,24 & 1,16 & 1,08 \\
\hline AA sulfurados (\%) & 0,86 & 0,83 & 0,77 & 0,75 & 0,86 & 0,83 & 0,77 & 0,75 \\
\hline
\end{tabular}

${ }^{1}$ Sem aditivo $(\mathrm{SA})=0,220$ g de casca de arroz; Com simbiótico $(\mathrm{SB})=0,200$ g de simbiótico +20 g de casca de arroz; e Com simbiótico + enzima $(\mathrm{SBE})=0,200 \mathrm{~g}$ de simbiótico $+20 \mathrm{~g}$ de enzima; ${ }^{2} \mathrm{SA}=0,226 \mathrm{~g}$ de casca de arroz; $\mathrm{SB}=0,200 \mathrm{~g}$ de simbiótico $+26 \mathrm{~g}$ de casca de arroz; e SBE = 0,200 g de simbiótico + 20 g de enzima +6 g de casca de arroz; ${ }^{3} \mathrm{SA}=0,222 \mathrm{~g}$ de casca de arroz; SB = 0,200 g de simbiótico +22 g de casca de arroz; e $\mathrm{SBE}=0,200 \mathrm{~g}$ de simbiótico $+20 \mathrm{~g}$ de enzima $+2 \mathrm{~g}$ de casca de arroz; ${ }^{4} \mathrm{SA}=0,228 \mathrm{~g}$ de casca de arroz; $\mathrm{SB}=$ 0,200 g de simbiótico + 28 g de casca de arroz; e SBE = 0,200 g de simbiótico + 20 g de enzima + 8 g de casca de arroz; *Núcleo vitamínico e mineral da Vaccinar Nutrição e Saúde Animal.

entre o total de ração fornecida e as sobras de ração no final de cada período); conversão alimentar (calculada pela razão entre o total de ração consumida e o ganho de peso no período, corrigida pelo peso das aves mortas no período); mortalidade foi anotada diariamente e expressa em percentual, pela relação entre o número de aves mortas no período e o número inicial de aves e o fator de produção (calculado pela razão entre o ganho de peso médio diário multiplicado pela viabilidade, dividido pela conversão alimentar, e, então, multiplicados por 100).

Aos 42 dias de idade, foram retiradas, ao acaso, cinco aves por boxe, sendo 20 aves por tratamento. As aves foram submetidas a oito horas de jejum e pesadas antes do abate no abatedouro da Faculdade de Medicina Veterinária e Zootecnia, UNESP - Campus de Botucatu. No abate, efetuou-se a sangria, após as aves serem aturdidas por choque elétrico. Em seguida, foi realizada evisceração e resfriamento em câmara fria, sem passar pelo chiller, e então as carcaças foram pesadas, cortadas e desossadas por procedimento tipo industrial. Em relação ao peso vivo, obtido na plataforma imediatamente antes do abate, obtiveram-se os seguintes rendimentos: carcaça (sem pés, cabeça, pescoço e vísceras comestíveis), pés, cabeça + pescoço e gordura abdominal (constituída pela gordura perianal e a gordura que envolve a moela e o proventrículo). Os rendimentos de peito, carne de peito, ossos de peito, pele de peito, pernas (comumente denominadas coxa e sobrecoxa), carne de pernas, ossos de pernas, pele de pernas, dorso, asas foram obtidos em relação ao peso da carcaça eviscerada.

A avaliação econômica foi realizada utilizando-se como parâmetros os valores de custos reais de pintinhos, ração, vacinas, medicamentos, cama e uma porcentagem fixa para todos os tratamentos representando os demais custos conforme planilha de custos utilizada pela APA - Associação Paulista de Avicultura (2003) para apuração do custo do quilograma de frango vivo. Para efeito de cálculo da receita, foram utilizados os preços de venda do quilograma de frango vivo aos 42 dias de idade, no mercado convencional e no alternativo.

Ciência Rural, v.37, n.1, jan-fev, 2007. 
Os dados obtidos foram analisados através do procedimento GLM do programa SAS (1996) e, quando necessário, as médias foram comparadas pelo teste de Student-Newman-Keuls (SNK) no nível de 5\% de probabilidade.

\section{RESULTADOS E DISCUSSÃO}

Aos 21 dias de idade não, houve efeito de aditivo, sistema de criação nem interação sistema de criação e aditivo para nenhuma das variáveis de desempenho, com exceção da conversão alimentar que apresentou efeito de sistema de criação (Tabela 2). Aves criadas no sistema convencional apresentaram melhor $(\mathrm{P}<0,05)$ conversão alimentar quando comparadas à conversão alimentar do sistema alternativo. A ausência de efeito do simbiótico sobre as variáveis de desempenho em frangos também foi verificada em diversos trabalhos citados por MENTEN (2002) e pode estar relacionado com o baixo desafio presente nos aviários experimentais. GONÇALVES (2003) verificou maior desempenho das aves criadas no sistema convencional quando comparadas às do sistema alternativo, o que não foi tão evidente nesta pesquisa, exceto pela melhor conversão alimentar nas aves do sistema convencional.

Houve efeito de aditivo e sistema de criação para o fator de produção e também interação entre aditivo e sistema de criação para conversão alimentar aos 42 dias de idade. Em relação às outras características de desempenho estudadas neste período, não houve efeito de aditivo ou sistema de criação e também interação entre os dois fatores.

O fator de produção foi menor $(\mathrm{P}<0,05)$ para aves alimentadas sem aditivo, quando comparadas às tratadas com simbiótico e simbiótico + enzima, as quais não diferiram entre si (Tabela 2). O sistema de criação convencional apresentou maior $(\mathrm{P}<0,05)$ fator de produção em comparação ao sistema de criação alternativo.

A conversão alimentar, dentro do sistema alternativo, foi melhor $(\mathrm{P}<0,05)$ para aves alimentadas com ração contendo simbiótico quando comparadas às alimentadas com simbiótico + enzima e sem aditivo, as quais não diferiram entre si (Tabela 3). No sistema convencional, não houve diferença significativa entre os aditivos adicionados à ração. Em relação aos aditivos, aves criadas no sistema convencional apresentaram melhor $(\mathrm{P}<0,05)$ conversão alimentar quando alimentadas com ração contendo simbiótico + enzima ou sem aditivo (Tabela 3). Esta melhora na conversão alimentar dos frangos suplementados com enzima está de acordo com resultados obtidos por SOTO-SALANOVA et al. (1996), podendo ser explicada por melhora na digestibilidade das rações (PACK \& BEDFORD, 1997) e aumento na energia digestível (RODRIGUES et al., 2003).

Não houve efeito $(\mathrm{P}>0,05)$ de aditivo e sistema de criação nem interação entre aditivo e sistema de criação para nenhuma das características de

Tabela 2 - Valores médios de peso final (PF), ganho de peso (GP), ganho de peso diário (GPD), consumo de ração (CR), conversão alimentar (CA), mortalidade (MO) e fator de produção (FP) nos períodos acumulados de 1 a 21 e de 1 a 42 dias de idade, segundo inclusão de aditivo e sistema de criação.

\begin{tabular}{|c|c|c|c|c|c|c|c|}
\hline \multirow{2}{*}{ Período (dias) } & \multirow{2}{*}{ Variáveis } & \multicolumn{3}{|c|}{ Aditivo } & \multicolumn{2}{|c|}{ Sistemas de criação } & \multirow{2}{*}{$\begin{array}{l}\text { CV } \\
(\%)\end{array}$} \\
\hline & & Sem aditivo & Simbiótico & Simbiótico+enzima & Convencional & Alternativo & \\
\hline \multirow{6}{*}{$1-21$} & PF, g & 834 & 860 & 851 & 860 & 838 & 4,44 \\
\hline & GP, g & 786 & 811 & 803 & 811 & 789 & 4,73 \\
\hline & GPD, g & 37 & 39 & 38 & 39 & 38 & 4,73 \\
\hline & CR, g & 1197 & 1206 & 1198 & 1197 & 1204 & 1,92 \\
\hline & CA & 1,53 & 1,49 & 1,49 & $1,48 \mathrm{a}$ & $1,53 \mathrm{~b}$ & 3,98 \\
\hline & $\mathrm{MO}, \%^{1}$ & 0,83 & 1,25 & 0,42 & 0,56 & 1,11 & 59,76 \\
\hline \multirow{7}{*}{$1-42$} & $P F, g$ & 2565 & 2604 & 2591 & 2599 & 2574 & 1,65 \\
\hline & GP, g & 2516 & 2554 & 2541 & 2550 & 2525 & 1,69 \\
\hline & GPD, g & 60 & 61 & 61 & 61 & 60 & 1,69 \\
\hline & $\mathrm{CR}, \mathrm{g}$ & 4561 & 4529 & 4547 & 4536 & 4556 & 2,50 \\
\hline & CA & $1,82 *$ & 1,78 & 1,79 & $1,78^{*}$ & 1,81 & 1,17 \\
\hline & $\mathrm{MO}, \%^{1}$ & 1,67 & 2,08 & 0,42 & 0,83 & 1,94 & 52,38 \\
\hline & $\mathrm{FP}^{2}$ & $324 b$ & 334 a & 337 a & 338 a & $325 \mathrm{~b}$ & 2,84 \\
\hline
\end{tabular}

${ }^{1}$ Mortalidade corrigida para $(\mathrm{x}+0,5){ }^{1 / 2} ;{ }^{2}$ Fator de Produção = ((GPD x Viabilidade $\left.) / C A\right)$ x 100; *Interação entre aditivo e sistema de criação;

${ }^{\mathrm{a}, \mathrm{b}}$ Médias na linha seguidas de letras diferentes diferem significativamente entre si $(\mathrm{P}<0,05)$ pelo teste de SNK. 
Tabela 3 - Valores médios de conversão alimentar para frangos de corte, no período acumulado de 1 a 42 dias de idade, segundo inclusão de aditivo e sistema de criação.

\begin{tabular}{lllll}
\hline & \multicolumn{4}{c}{ Aditivo } \\
\cline { 2 - 4 } $\begin{array}{l}\text { Sistema de } \\
\text { criação }\end{array}$ & $\begin{array}{c}\text { Sem } \\
\text { aditivo }\end{array}$ & Simbiótico & $\begin{array}{c}\text { Simbiótico + } \\
\text { enzima }\end{array}$ \\
\hline Convencional & $1,79 \mathrm{~A}$ & 1,79 & $1,76 \mathrm{~A}$ & 0,76 \\
Alternativo & $1,85 \mathrm{bB}$ & $1,77 \mathrm{a}$ & $1,82 \mathrm{bB}$ & 1,50 \\
$\mathrm{CV}(\%)$ & 0,93 & 1,46 & 1,15 & \\
\hline
\end{tabular}

${ }^{\mathrm{a}, \mathrm{b}}$ Médias na linha seguidas de letras minúsculas iguais não diferem significativamente entre si $(\mathrm{P}>0,05)$ pelo teste de SNK;

${ }^{\mathrm{A}, \mathrm{B}}$ Médias na coluna seguidas de letras maiúsculas diferentes

diferem significativamente entre si $(\mathrm{P}<0,05)$ pelo teste de SNK.

rendimento de carcaça, cortes e gordura abdominal de frangos aos 42 dias de idade (Tabela 4). GONÇALVES (2003) também não observou diferença significativa entre sistemas de criação no rendimento de carcaça e partes de frangos aos 49 dias de idade. Em relação ao uso de aditivo, LODDI (1998) verificou melhora no rendimento de carcaça com o uso de probiótico, o que não está de acordo com os resultados da presente pesquisa.

A inclusão de simbiótico e simbiótico + enzima aumentou o custo por quilograma das rações em U\$ 0,008 e 0,011, respectivamente, ao comparar-se às rações sem aditivo, no sistema convencional e no alternativo (Tabela 5), o que refletiu num aumento no custo total de produção. Quando não se utilizou aditivo nas rações, o lucro/ave foi superior em US\$ 0,025 e US $\$$ 0,033, em relação às aves que receberam simbiótico e simbiótico + enzima, quando criadas no sistema convencional e superior em US\$ 0,002 e 0,016, quando criadas no sistema alternativo.

No sistema alternativo, o custo com pintinhos é maior devido à vacinação contra coccidiose (Tabela 5). No entanto, o preço pago pelo kg do frango vivo também é maior quando comparado ao sistema convencional, de acordo com BUTOLO (1999). A receita por ave foi maior para as aves criadas de forma alternativa, quando comparada às do sistema convencional, o que, conseqüentemente, levou também ao lucro maior por ave, conforme relatado por GONÇALVES (2003). O lucro por ave do sistema alternativo foi maior em US\$1,027; 1,050 e 1,044 para as aves que não receberam aditivos, com simbiótico e simbiótico + enzima, respectivamente, quando se compara os sistemas de criação.

\section{CONCLUSÃO}

O uso de simbiótico e simbiótico + enzima favorece o desempenho de frangos de corte aos 42 dias de idade e não influencia o rendimento de carcaça, cortes e gordura abdominal, tanto no sistema convencional como no alternativo, sendo que estes aditivos aumentam os custos de produção em ambos os sistemas. O sistema alternativo proporciona maior retorno econômico, apesar do menor fator de produção.

Tabela 4 - Valores médios de rendimento de carcaça e cortes de frangos de corte abatidos aos 42 dias de idade, segundo inclusão de aditivo e sistema de criação.

\begin{tabular}{|c|c|c|c|c|c|c|}
\hline \multirow{2}{*}{ Variáveis (\%) } & \multicolumn{3}{|c|}{ Aditivo } & \multicolumn{2}{|c|}{ Sistema de criação } & \multirow{2}{*}{$\begin{array}{l}\text { CV } \\
\text { (\%) }\end{array}$} \\
\hline & Sem aditivo & Simbiótico & Simbiótico+enzima & Convencional & Alternativo & \\
\hline Carcaça eviscerada $^{1}$ & 70,74 & 71,19 & 71,16 & 71,10 & 70,95 & 2,08 \\
\hline Cabeça e pescoço ${ }^{1}$ & 5,49 & 5,72 & 5,24 & 5,54 & 5,42 & 11,45 \\
\hline Pés ${ }^{1}$ & 4,31 & 4,42 & 4,42 & 4,35 & 4,42 & 12,04 \\
\hline Gordura abdominal $^{1}$ & 1,74 & 1,71 & 1,71 & 1,62 & 1,82 & 28,17 \\
\hline Asas $^{2}$ & 11,32 & 11,15 & 11,18 & 11,16 & 11,28 & 4,28 \\
\hline Peito $^{2}$ & 32,67 & 33,24 & 32,91 & 33,28 & 32,59 & 4,51 \\
\hline Pernas $^{2}$ & 33,33 & 33,48 & 33,36 & 33,09 & 33,69 & 3,99 \\
\hline Dorso $^{2}$ & 22,83 & 22,32 & 22,48 & 22,51 & 22,58 & 4,95 \\
\hline Ossos de peito ${ }^{2}$ & 4,83 & 4,81 & 4,86 & 4,77 & 4,90 & 10,98 \\
\hline Pele de peito ${ }^{2}$ & 2,88 & 2,93 & 2,76 & 2,86 & 2,85 & 18,49 \\
\hline Carne de peito $^{2}$ & 24,63 & 25,08 & 24,89 & 25,25 & 24,47 & 6,10 \\
\hline Ossos de pernas ${ }^{2}$ & 7,13 & 7,11 & 7,04 & 7,09 & 7,10 & 8,06 \\
\hline Pele de pernas ${ }^{2}$ & 3,64 & 3,64 & 3,58 & 3,51 & 3,73 & 12,14 \\
\hline Carne de pernas ${ }^{2}$ & 22,49 & 22,69 & 22,70 & 22,44 & 22,81 & 5,19 \\
\hline
\end{tabular}

${ }^{1}$ Rendimento de carcaça eviscerada, cabeça e pescoço, pés ou gordura abdominal (\%) = (peso da carcaça eviscerada, cabeça e pescoço, pés ou gordura abdominal, g/peso vivo, g)*100; ${ }^{2}$ Rendimento de cortes (\%) = (peso dos cortes, g/peso da carcaça eviscerada, g)*100. 
Tabela 5 - Análise econômica* segundo inclusão de aditivo e sistema de criação de frangos de corte.

\begin{tabular}{|c|c|c|c|c|c|c|}
\hline \multirow[t]{2}{*}{ Parâmetros } & \multicolumn{3}{|c|}{ Sistema convencional } & \multicolumn{3}{|c|}{ Sistema alternativo } \\
\hline & Sem aditivo & Simbiótico & Simbiótico+enzima & Sem aditivo & Simbiótico & Simbiótico+enzima \\
\hline Total de aves & 100 & 100 & 100 & 100 & 100 & 100 \\
\hline Mortalidade, \% & 1,67 & 0,00 & 0,83 & 1,67 & 4,17 & 0,00 \\
\hline Peso vivo final, kg & 258 & 261 & 261 & 255 & 260 & 257 \\
\hline Consumo de ração, kg & 450 & 458 & 452 & 462 & 448 & 457 \\
\hline Custo/kg ração, US\$ & 0,18 & 0,19 & 0,19 & 0,18 & 0,19 & 0,19 \\
\hline Custo da ração ${ }^{1}$, US\$ & 82,13 & 87,05 & 87,27 & 83,76 & 84,61 & 87,86 \\
\hline Custo dos pintos, US\$ & 0,09 & 0,09 & 0,09 & 0,12 & 0,12 & 0,12 \\
\hline Outros custos ${ }^{2}, \mathrm{US} \$$ & 0,10 & 0,10 & 0,10 & 0,10 & 0,10 & 0,10 \\
\hline Custo total, US\$ & 100,36 & 105,84 & 106,06 & 104,88 & 106,30 & 109,56 \\
\hline Preço/kg vivo ${ }^{3}$, US\$ & 0,43 & 0,43 & 0,43 & 0,86 & 0,86 & 0,86 \\
\hline Receita total, US\$ & 109,01 & 112,18 & 111,49 & 214,54 & 212,98 & 219,47 \\
\hline Lucro total, US\$ & 8,66 & 6,34 & 5,43 & 109,66 & 106,68 & 109,91 \\
\hline Custo/ave, US\$ & 1,02 & 1,06 & 1,07 & 1,07 & 1,11 & 1,10 \\
\hline Receita/ave, US\$ & 1,09 & 1,12 & 1,12 & 2,14 & 2,13 & 2,20 \\
\hline Lucro/ave, US\$ & 0,09 & 0,06 & 0,06 & 1,12 & 1,11 & 1,10 \\
\hline
\end{tabular}

*Com base na planilha de custos da APA - Associação Paulista de Avicultura (2003); ${ }^{1}$ Cotações de milho e farelo de soja baseadas na Associação Paulista de Avicultura (APA) de janeiro de 2003; ${ }^{2}$ Desinfecção, vacinas e medicamentos, energia elétrica, gás aquecimento, mãode-obra e encargos, encargos sociais sobre a produção, manutenção e reparos (APA, 2003); ${ }^{3}$ Estimativa com base no preço do kg de frango vivo convencional, do kg de frango resfriado convencional e do kg de frango resfriado alternativo, em janeiro de 2003.

\section{REFERÊNCIAS}

ANDREATTI FILHO, R.L.; SAMPAIO, H.M. Probióticos e Prebióticos: realidade na avicultura industrial moderna. Revista da Educação Continuada do CRMV-SP, v.2, n.3, p.59-71, 1999.

APA - Associação Paulista de Avicultura. Estatística: apuração do custo quilo do frango vivo na granja. Acesso em 15 jan. 2003. On line. Disponível em:<http://www.apa.com.br/ framesta.htm>.

BUTOLO, J.E. Uso de aditivos na alimentação de aves: frangos de corte. In: SIMPÓSIO SOBRE AS IMPLICAÇÕES SÓCIOECONÔMICAS DO USO DE ADITIVOS NA PRODUÇÃO ANIMAL, 1999, Campinas, SP. Anais... Campinas: CBNA, 1999. p.85-94.

DEMATTÊ FILHO, L.C. Aditivos em dietas para frangos de corte criados em sistema alternativo. 2004. $86 \mathrm{f}$. Dissertação (Mestrado em Zootecnia) - Faculdade de Medicina Veterinária e Zootecnia, Universidade Estadual Paulista, Botucatu.

FULLER, R. Probiotics in man and animals. A review. Journal of Applied Bacteriology, v.66, p.365-378, 1989.

GARCIA, E.R.M. et al. Efeito da suplementação enzimática em rações com farelo de soja e soja integral extrusada sobre a digestibilidade de nutrientes, o fluxo de nutrientes na digesta ileal e o desempenho de frangos. Revista Brasileira de Zootecnia, v.29, n.5, p.1414-1426, 2000.

GONÇALVES, J.C. Silagem de grãos úmidos de milho para frangos de corte nos sistemas convencional e alternativo. 2003. 45f. Dissertação (Mestrado em Zootecnia) - Faculdade de Medicina Veterinária e Zootecnia, Universidade Estadual Paulista, Botucatu.
LODDI, M.M. Aspectos produtivos e qualitativos do uso de probióticos para frangos de corte. 1998. 60f. Dissertação (Mestrado em Zootecnia) - Faculdade de Medicina Veterinária e Zootecnia, Universidade Estadual Paulista, Botucatu.

MACHADO, J.N. Uso de probióticos, prebióticos e simbióticos. Alimentação Animal, v.5, n.20, p.12-14, 2000.

MENTEN, J.F.M. Probióticos, prebióticos e aditivos fitogênicos na nutrição de aves. In: SIMPÓSIO SOBRE INGREDIENTES NA ALIMENTAÇÃO ANIMAL, 2002, Uberlândia, MG. Anais... Campinas: CBNA, 2002. p.251-276.

PACK, M.; BEDFORD, M. Feed enzymes for corn-soybean broiler diets. A new concept to improve nutritional value and economics. Poultry Science, v.13, n.1, p.87-93, 1997.

RODRIGUES, P.B. et al. Desempenho de frangos de corte, digestibilidade de nutrientes e valores energéticos de rações formuladas com vários milhos, suplementadas com enzimas. Revista Brasileira de Zootecnia, v.32, n.1, p.171-182, 2003.

ROSTAGNO, H.S. et al. Tabelas brasileiras para aves e suínos: composição de alimentos e exigências nutricionais. Viçosa: UFV, 2000. 141p.

SAS Institute, SAS/STAT. User's guide. Version 6.11. 4.ed. Cary: SAS Institute, 1996. 842p. V.2.

SCHWARZ, K.K. Substituição de antimicrobianos por probióticos e prebióticos na alimentação de frangos de corte. 2002. 46f. Dissertação (Mestrado em Ciências Veterinárias) - Universidade Federal do Paraná, Curitiba.

SOTO-SALANOVA, M.F. et al. Uso de enzimas em dietas de milho e soja para frangos de corte. In: CONFERÊNCIA APINCO DE CIÊNCIA E TECNOLOGIA AVÍCOLAS, 1996, Campinas, SP. Anais... Campinas: FACTA, 1996. p.71-78. 